\title{
Diffusion regimes at nanoelectrode ensembles in different ionic liquids
}

\author{
Paolo Ugo ${ }^{\mathrm{a}, *}$, Ligia M. Moretto ${ }^{\mathrm{a}}$, Manuela De Leo ${ }^{\mathrm{a}}$, Andrew P. Doherty ${ }^{\mathrm{b}}$, \\ Chiara Vallese ${ }^{\mathrm{a}}$, Sreekanth Pentlavalli ${ }^{\mathrm{b}}$ \\ a Department of Physical Chemistry, University of Venice, Santa Marta 2137, 30123, Venice, Italy \\ ${ }^{\mathrm{b}}$ The School of Chemistry and Chemical Engineering, Queen's University of Belfast, David Keir Building, Stranmillis Road, Belfast, N.I. BT5AG, UK
}

\section{A R T I C L E I N F O}

\section{Article history:}

Received 9 September 2009

Received in revised form

18 December 2009

Accepted 21 December 2009

Available online 11 January 2010

\section{Keywords:}

Nanoelectrodes

Arrays

Ionic liquids

Diffusion

Voltammetry

\begin{abstract}
A B S T R A C T
The electrochemical and diffusion behaviour of different redox probes in different ionic liquids is studied at gold nanoelectrode ensembles (NEEs) in comparison with millimetre sized gold (Au-macro) and glassy carbon (GC) disk electrodes. The redox probes are neutral ferrocene (Fc), the ferrocenylmethyltrimetylammonium cation $\left(\mathrm{FA}^{+}\right)$and the ferrocenylmonocarboxylate anion $\left(\mathrm{FcCOO}^{-}\right)$. The ILs are the dicyanamide, $\left[\mathrm{N}(\mathrm{CN})_{2}\right]$ or bis(trifluoromethylsulfonyl)amide), $\left[\mathrm{N}(\mathrm{Tf})_{2}\right]$ salts of the following cations: 1-butyl-3-methylimidazolium, [BMIm], 1-butyl-3-methylpyrrolidonium, [BMPy], or tris(nhexyl)tetradecylphosphonium $\left[\mathrm{P}_{14,666}\right]$. These ILs are characterized by different viscosities, ranging from 32 to $277 \mathrm{cP}$. The cyclic voltammetric behaviour of the redox probes is reversible and diffusion controlled at GC electrodes. Diffusion coefficients $(D)$ calculated by the Randles-Sevcik equation scales inversely with the IL viscosity, ranging from $2 \times 10^{-8}$ to $3 \times 10^{-7} \mathrm{~cm}^{2} \mathrm{~s}^{-1}$. Ionic solutes, namely $\mathrm{FA}^{+}$and $\mathrm{FcCOO}^{-}$, present slightly lower $D$ values than neutral Fc. At the Au-macro the electrochemical behaviour of the redox probes is diffusion controlled in the ILs containing the $\left[\mathrm{N}(\mathrm{Tf})_{2}\right]$ anion, while it involves relevant adsorption processes in the $\left[\mathrm{N}(\mathrm{CN})_{2}\right]$ containing electrolyte. For this reason the diffusion at gold NEEs is studied only in the former ILs.

The CVs of the redox probes at the NEEs are peak shaped at low scan rate $(v)$, while they are sigmoidally shaped at high $v$, but with some shift between forward and backward patterns. This is indicative of the occurrence of a total overlap (TO) diffusion condition when $v$ is low which becomes a mixed diffusion layers (MDL) regime, with only a partial overlapping of individual diffusion layers, at high $v$ values. In the most viscous IL, namely $\left[\mathrm{P}_{14,666}\right]\left[\mathrm{N}(\mathrm{Tf})_{2}\right]$, at $v$ higher than $0.8 \mathrm{~V} \mathrm{~s}^{-1}$, a plateau current independent on the scan rate is achieved, indicating the tendency to reach the pure radial regime in this IL. The $v$ values at which the transition between TO and MDL is observed scales directly with $D$ and inversely with the IL viscosity. This behaviour is interpreted on the basis of the dependence of individual diffusion layers at each nanoelectrode on redox probe/IL interaction which fits with existing theoretical models very recently developed for nanoelectrode arrays.
\end{abstract}

(c) 2010 Elsevier Ltd. All rights reserved.

\section{Introduction}

Novel interfaces in which both the solid and liquid components present peculiar characteristics are increasingly used in electrochemistry. The present study focuses on the electrochemical behaviour of a quite complex electrode/solution interface where the electrode is the surface of an ensemble of gold nanoelectrodes and the electrolyte is an ionic liquid (IL).

ILs are salts composed by a large organic cation and a relatively small anion; they present peculiar properties both from a fundamental and applicative viewpoint. For the electrochemist they are intriguing aprotic solvents which can stabilize electro-

\footnotetext{
* Corresponding author.

E-mail address: ugo@unive.it (P. Ugo).
}

generated reactive species or water insoluble redox probes as well as allow the wide extension of the accessible potential window [1-4]. Particularly interesting is the role of ILs in ruling the mass transport of electroactive analytes to the electrode/solution interface [5-8]. Moreover, the nature and characteristics of ILs can influence dramatically the electron transfer kinetics $[9,10]$. The large differences in size and ionic mobility of the cation and anion can originate selective solvation of solutes with different ionic charge. For instance, for the redox couple $\mathrm{O}_{2} / \mathrm{O}_{2}{ }^{-}$it was observed that in some RTIL the diffusion coefficient for the neutral species is significantly larger than the one of the superoxide anion, this reflecting in a dramatic asymmetry of the voltammetric peak currents for the anodic and cathodic processes [11,12]. In some ILs, a complex concentration dependence of the diffusion coefficients was observed, at least in certain concentration range $[13,14]$. 
Although the electrochemical behaviour of ILs has been quite widely investigated by using millimetre or micrometre sized electrodes [3,4], only one recent report from our lab [15] introduced the study of complex nanostructured electrode systems such as nanoelectrode ensembles (NEEs) in a specific IL, namely, 1-butyl-3-

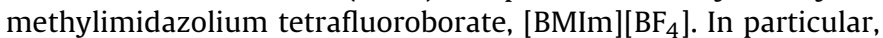
this first investigation indicated that the high viscosity of this ionic liquid (approximately 100-150 cP) caused a change in diffusion regime with respect to less viscous electrolyte solution, e.g. aqueous or acetonitrile solutions.

The nanoelectrode ensembles used in our laboratory are indeed prepared by electroless deposition of gold nanodisk electrodes using commercially available track-etched polycarbonate membranes as templates $[16,17]$. Templated NEEs prepared by the procedure introduced by Menon and Martin in 1995 [18], are increasingly studied and applied by many laboratories $[19,20]$.

NEEs can be considered as partially blocked electrodes $[18,21-23]$, being composed by a very large number of very small ultramicroelectrodes, all statistically equivalent since their large number make border effects negligible [24,25]. From a general viewpoint, arrays of micro and nanoelectrodes can exhibit distinct voltammetric response regimes depending on the thickness of the diffusion layer and distance between the nanoelectrode elements [16,18,22-25]. Three distinct limit cases can be achieved: (A) total overlap (TO) regime: when radial diffusion boundary layers overlap totally (hemi-distance between nanoelectrodes smaller than radius of diffusion hemispheres); (B) pure radial (PR): when the nanoelectrodes behave independently (hemi-distance between nanoelectrodes larger than radius of diffusion hemispheres); (C) linear active (LA): when the nanoelectrodes behave as isolated planar electrodes, each under semi-infinite linear diffusion. In principle, for a fixed geometry of the array, it could be possible to move from TO to PR to LA by increasing the voltammetric scan rate. Intermediate regimes can be also observed: for experimental conditions between TO and PR the so-called mixed diffusion layers (MDL) regime can be established. Under these conditions partial overlap of diffusion layers occurs. Theoretical models have been developed for ordered [22,25-27] and random [28] arrays of electrodes.

In water solutions, the diffusion regime usually observed at NEEs fabricated from commercial track-etched membranes is the TO; only in the case of custom made polycarbonate membranes, Martin et al. were able to achieve the PR regime [29]. The limits which hinder reaching the PR regime with NEEs made with commercially available track-etch membranes are the following:

- the pores in the membrane (and the templated nanodisk electrodes) are randomly distributed;

- the average distance, $d$, between the nanoelectrodes is fixed and ruled by the producer.

This derives from the procedure used to prepare the membranes, that is the tracking of a polycarbonate film with high energy radiation in a nuclear reactor or ion accelerator, followed by development of the tracks by etching in alkaline solution [16]. The density of pores per unit surface is determined by the radiation source and the exposure time during the tracking, while the diameter of the pores is determined by the etching time. Commercially available membranes contain monodisperse pores with 10 , $30,200 \mathrm{~nm}$ or larger diameter and with a pore density of $10^{8}$ to $10^{9}$ pores $/ \mathrm{cm}^{2}$.

At fixed scan rate, the thickness, $\delta$, of the diffusion layer around each nanoelectrode depends on the square root of the diffusion coefficient $(D)$ of the redox analyte [30], according to: $\delta=(\Pi D t)^{1 / 2}$. $D$ values are themselves inversely proportional to the viscosity of the solvent medium, given by the Stokes-Einstein equation [30]; as
Table 1

Surveys of the literature data on the viscosities, $\eta$, of the studied ionic liquids.

\begin{tabular}{lrll}
\hline IL & $\eta / \mathrm{CP}$ & $T /{ }^{\circ} \mathrm{C}$ & Ref. \\
\hline$\left[\right.$ BMIm] $\left[\mathrm{N}(\mathrm{CN})_{2}\right]$ & 32 & 28 & {$[32]$} \\
{$[$ BMPy $]\left[\mathrm{N}(\mathrm{CN})_{2}\right]$} & 50 & 25 & {$[33]$} \\
{$[\mathrm{BMIm}]\left[\mathrm{N}(\mathrm{Tf})_{2}\right]$} & 57 & 20 & {$[31]$} \\
{$[\mathrm{BMPy}]\left[\mathrm{N}(\mathrm{Tf})_{2}\right]$} & 89 & 25 & {$[34]$} \\
{$\left[\mathrm{P}_{14,666}\right]\left[\mathrm{N}(\mathrm{Tf})_{2}\right]$} & 277 & 25 & {$[35]$} \\
\hline
\end{tabular}

a consequence, changes in viscosity can reflect in dramatic changes in the diffusion regime.

In order to investigate with more insight on the role of solvent viscosity on the diffusion regime at NEEs, in the present work we study the electrochemical behaviour at NEEs of different redox analytes in a series of different ionic liquids. The ILs studied were salts of two different anions, namely, dicyanamide, $\left[\mathrm{N}(\mathrm{CN})_{2}\right]$, and bis(trifluoromethylsulfonyl)amide), [N(Tf $\left.)_{2}\right]$. The cations of the salts were 1-butyl-3-methylimidazolium, [BMIm], 1-butyl-3-methylpyrrolidonium, [BMPy], and tris(nhexyl)tetradecylphosphonium $\left[\mathrm{P}_{14,666}\right]$. As outlined in Table 1 , this combination of anions and cations, furnishes five different ILs characterized by different viscosities, $\eta$, which range from 32 to $277 \mathrm{cP}$.

The analytes are three different redox probes containing the ferrocenyl group and differing each other for ionic charge; they are neutral ferrocene ( $\mathrm{Fc}$ ), ferrocenylmethyltrimetylammonium cation $\left(\mathrm{FA}^{+}\right)$and ferrocenylmonocarboxylic acid $(\mathrm{FcCOOH})$. On the basis of the basicity of the anions $\left[\mathrm{N}(\mathrm{Tf})_{2}\right]$ and $\left[\mathrm{N}(\mathrm{CN})_{2}\right]^{-}[36]$ and of the acidity of $\mathrm{FcCOOH}\left(\mathrm{p} K_{\mathrm{a}}=6.7\right.$ in water/ethanol [37]), it is reasonable that $\mathrm{FcCOOH}$ be completely dissociated to the ferrocenyl carboxylate anion.

Preliminary experiments at millimetre sized electrodes were performed to measure the diffusion coefficients of the redox probes in the different ILs as well as to gain information of the general electrochemical behaviour of the redox probes in the ILs using two different electrode materials, namely, gold (of which are made the NEEs) and glassy carbon (GC).

\section{Experimental}

\subsection{Apparatus and procedures}

Voltammetric measurements were performed with a $\mathrm{CH} 660 \mathrm{~A}$ apparatus controlled via PC, using IR-drop compensation. All electroanalytical measurements were carried out in a three-electrodes cell of small volume ( $5 \mathrm{~mL}$ ). The working electrode was either a NEE, a glassy carbon electrode (GCE, diameter $5 \mathrm{~mm}$ ) or an Au-disk electrode, millimetre sized (diameter $3 \mathrm{~mm}$ ), the counter electrode was a platinum coil and an Ag wire was used as quasi-reference electrode. ILs were dried overnight in a vacuum oven at $40^{\circ} \mathrm{C}$ before use, after treatment with activated molecular sieves. It was previously demonstrated that this procedure is able to remove trace

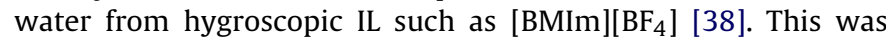
confirmed for the hydrophobic ILs studied here, since no water reduction peak was observed in the $\mathrm{CV}$ recorded after performing the above described vacuum treatment. All measurements were performed at room temperature $\left(20 \pm 1^{\circ} \mathrm{C}\right)$, operating under a nitrogen atmosphere; the purging gas fluxed trough traps loaded with concentrated sulphuric acid, in order to prevent eventual entrance into the cell of humidity from the room environment.

\subsection{Preparation of the nanoelectrode ensembles}

Polycarbonate filtration membranes (SPI-Pore, $47 \mathrm{~mm}$ filter diameter, $6 \mu \mathrm{m}$ filter thickness) with nominal pore diameter of 


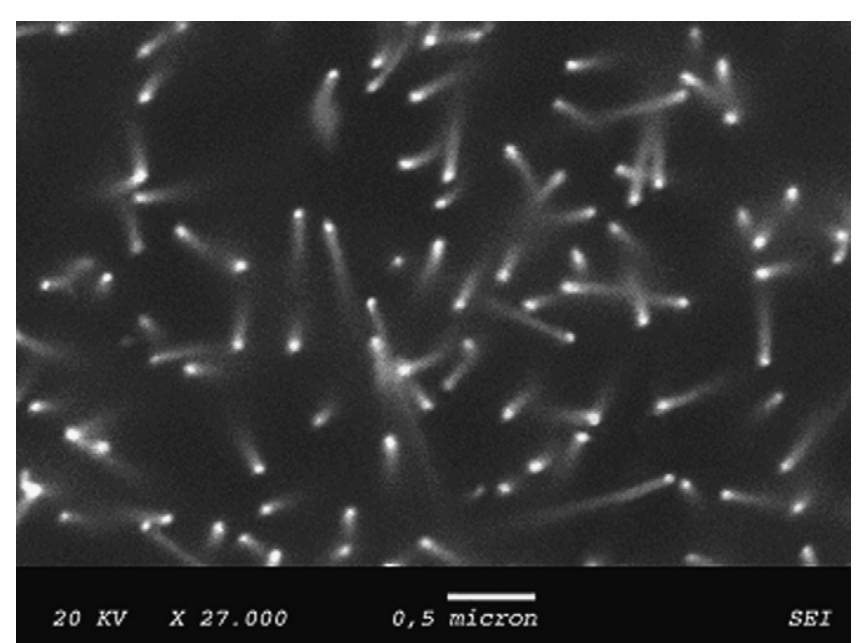

Fig. 1. SEM image of a NEE.

$30 \mathrm{~nm}$, pore density of $6 \times 10^{8}$ pores $\mathrm{cm}^{-2}$ and coated by the producer with polyvinylpyrrolidone were used as the templates to prepare the NEEs, following the Menon and Martin procedure [18] with recent updates [39]. Briefly, after wetting for $2 \mathrm{~h}$ in methanol, the polycarbonate template membrane was sensitized with $\mathrm{Sn}^{2+}$ by immersion into a solution that was $0.026 \mathrm{M}$ in $\mathrm{SnCl}_{2}$ and $0.07 \mathrm{M}$ in trifluoroacetic acid in 50:50 methanol-water for $5 \mathrm{~min}$. After rinsing with methanol for $5 \mathrm{~min}$, the sensitized membrane was immersed for $10 \mathrm{~min}$ in $0.029 \mathrm{M} \mathrm{Ag}\left[\left(\mathrm{NH}_{3}\right)_{2}\right] \mathrm{NO}_{3}$. The membrane was then immersed into the Au plating bath which was $7.9 \times 10^{-3} \mathrm{M}$ in $\mathrm{Na}_{3} \mathrm{Au}\left(\mathrm{SO}_{3}\right)_{2}, 0.127 \mathrm{M}$ in $\mathrm{Na}_{2} \mathrm{SO}_{3}$. After waiting $30 \mathrm{~min}, 0.625 \mathrm{M}$ formaldehyde was added to the plating bath; this delay time was introduced here since it allows one to separate the formation of the first gold nuclei (produced by galvanic displacement of metallic $\mathrm{Ag}^{0}$ nuclei with $\mathrm{Au}^{0}$ nuclei) from the following catalytic growth of these nuclei by further gold deposition caused by formaldehyde. The temperature of the bath was $0-2{ }^{\circ} \mathrm{C}$. Electroless deposition was allowed to proceed for $15 \mathrm{~h}$, after which an additional $0.3 \mathrm{M}$ formaldehyde was added. Deposition was continued for another $9 \mathrm{~h}$, after which the membrane was rinsed with water and immersed in $10 \% \mathrm{HNO}_{3}$ for $12 \mathrm{~h}$. The membrane was then rinsed again with water and dried. For the final assembly of the NEEs, see previously published procedures [16].

The geometric area (area of the nanoelectrodes + area of the insulator among them) was $0.07 \mathrm{~cm}^{2}$, nanodisk diameters measured by SEM was $40-50 \mathrm{~nm}$ [4]. A SEM image of a NEE used in this work is shown in Fig. 1; for further details see Ref. [40].

Commercial gold electroless plating solution Oromerse Part B was purchased from Technic Inc.

\subsection{Chemicals}

(Ferrocenylmethyl)dimethylamine (Aldrich) was reacted with methyl iodide to form the quaternary ammonium iodide [41]. This was then converted to (ferrocenylmethyl) trimethylammonium hexafluorophosphate $\left(\mathrm{FA}^{+} \mathrm{PF}_{6}{ }^{-}\right)$using $\mathrm{AgPF}_{6}$.

Ferrocene $(\mathrm{Fc})$ and ferrocenylmonocarboxylic acid $(\mathrm{FcCOOH})$ were purchased from Sigma.

[BMIm], [BMPy] and [ $\left.\mathrm{P}_{14,666}\right]$ ionic liquids were prepare by ion metathesis reaction of their chloride salts with either $\mathrm{NaN}(\mathrm{CN})_{2}$ or $\operatorname{LiN}(\mathrm{Tf})_{2}$ in dichloromethane (DCM) solvent. The procedure involves firstly dissolving the quaternary ammonium or phosphonium cation salt in DCM followed by the addition of 1.2 equivalents of the anion salt. Reaction mixtures were stirred for $24 \mathrm{~h}$ after which the precipitated inorganic salts (either $\mathrm{NaCl}$ or $\mathrm{LiCl}$ ) were removed by filtration. The DCM (filtrate) solution of the crude ionic liquid was washed $(5 \times)$ with deionised water. After washing, DCM was removed under vacuum. Activated carbon was then added to the ionic liquid and stirred for $24 \mathrm{~h}$. Finally, the activated carbon was removed by filtration through an alumina column under vacuum. All other reagents were of analytical grade and used as received.

\section{Results and discussion}

\subsection{GC-macro}

We examined at first the main features of the electrochemical behaviour of $\mathrm{Fc}, \mathrm{FcCOO}^{-}$and $\mathrm{FA}^{+}$in the investigated ILs, focusing in particular on the reversibility and diffusion control of the redox process in order to evaluate diffusion coefficient values. This preliminary characterization was performed using millimetre sized GC disk electrodes. Under these conditions, for all the redox probes and ILs here examined, a diffusion controlled reversible or quasireversible electrochemical behaviour was observed. As an example, Fig. $2 A$ shows the typical CV patterns recorded with the GCE at different scan rates in [BMIm] $\left[\mathrm{N}(\mathrm{CN})_{2}\right]$ containing $1 \mathrm{mM}$ Fc. For scan rates $\geq 0.050 \mathrm{~V} / \mathrm{s}$, the peak to peak separation $\left(\Delta E_{\mathrm{p}}\right)$ is $0.065 \mathrm{~V}$ and
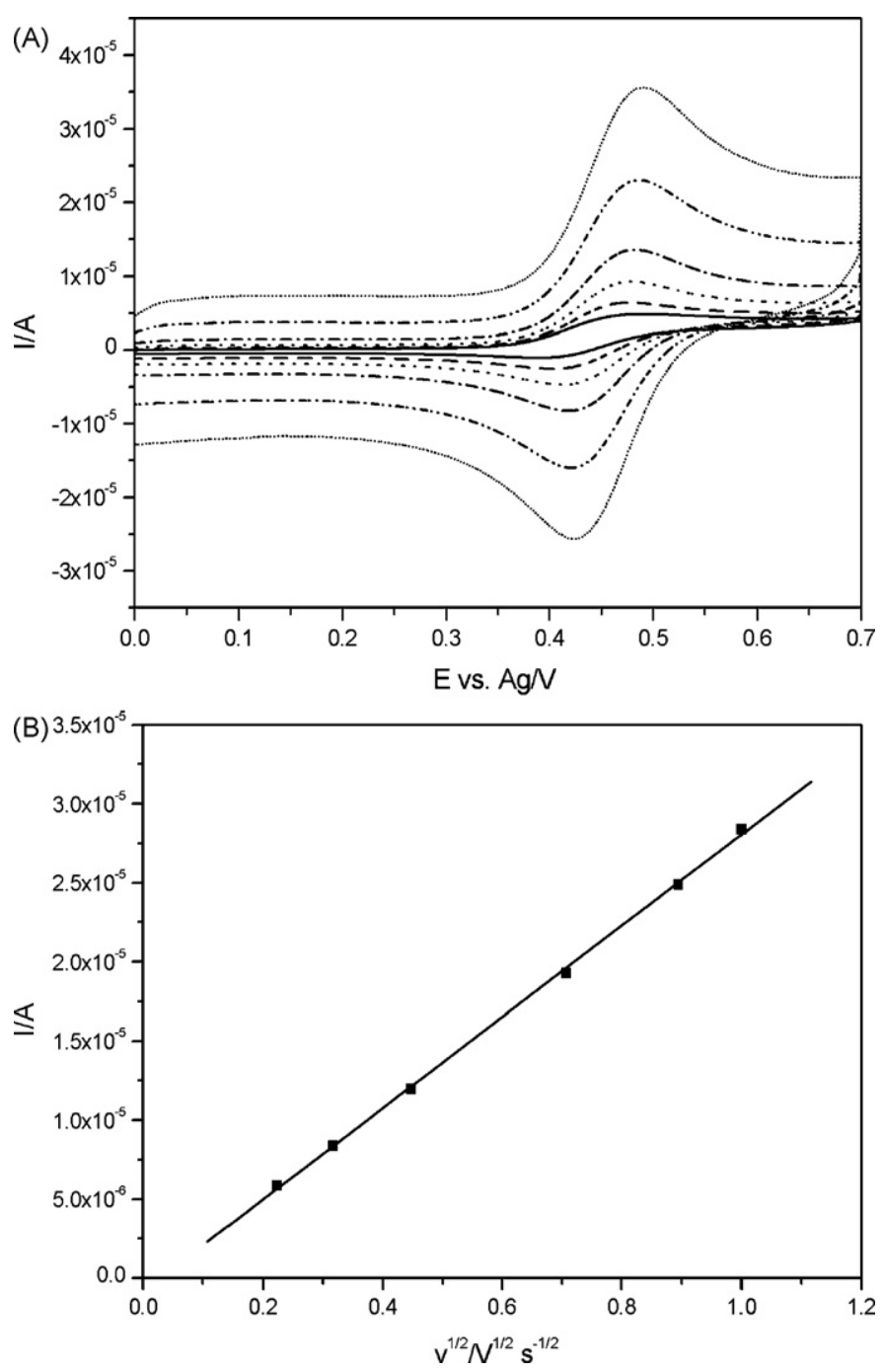

Fig. 2. (A) Cyclic voltammograms of $1 \mathrm{mM}$ Fc in [BMIm] $\left.\mathrm{N}(\mathrm{CN})_{2}\right]$ recorded at GCE (geometric area $0.19 \mathrm{~cm}^{2}$ ) at different scan rates: $20,50,100,200,500,1000 \mathrm{mV} \mathrm{s}^{-1}$; peak currents scale with the scan rate. (B) Dependence of the anodic peak current on the square root of the scan rate. 
Table 2

Diffusion coefficients measured by cyclic voltammetry at the glassy carbon electrode in solution containing $1 \mathrm{mM}$ redox probe in different ionic liquids.

\begin{tabular}{|c|c|c|c|}
\hline & $D(\mathrm{Fc}) / 10^{-7} \mathrm{~cm}^{2} \mathrm{~s}^{-1}$ & $D\left(\mathrm{FcCOO}^{-}\right) / 10^{-7} \mathrm{~cm}^{2} \mathrm{~s}^{-1}$ & $D\left(\mathrm{FA}^{+}\right) / 10^{-7} \mathrm{~cm}^{2} \mathrm{~s}^{-1}$ \\
\hline$[\mathrm{BMIm}]\left[\mathrm{N}(\mathrm{CN})_{2}\right]$ & $3.2 \pm 0.3$ & $2.0 \pm 0.4$ & $1.2 \pm 0.4$ \\
\hline$[\mathrm{BMPy}]\left[\mathrm{N}(\mathrm{CN})_{2}\right]$ & $2.5 \pm 0.3$ & $2.0 \pm 0.4$ & $1.2 \pm 0.4$ \\
\hline$[\mathrm{BMIm}]\left[\mathrm{N}(\mathrm{Tf})_{2}\right]$ & $2.9 \pm 0.5$ & $0.9 \pm 0.2$ & n.m. ${ }^{\mathrm{a}}$ \\
\hline$[\mathrm{BmPy}]\left[\mathrm{N}(\mathrm{Tf})_{2}\right]$ & $0.7 \pm 0.3$ & $0.4 \pm 0.2$ & $0.5 \pm 0.2$ \\
\hline$\left[\mathrm{P}_{14,666}\right]\left[\mathrm{N}(\mathrm{Tf})_{2}\right]$ & $0.2 \pm 0.05$ & n.m. ${ }^{\mathrm{a}}$ & n.m..$^{\mathrm{a}}$ \\
\hline
\end{tabular}

a n.m. = not measured.

$E_{1 / 2}$, calculated as $E_{1 / 2}=\left(E_{\mathrm{pf}}+E_{\mathrm{pb}}\right) / 2$, is independent of the scan rate. The anodic peak current values $\left(I_{\mathrm{pf}}\right)$ scale linearly with the square root of the scan rate (see Fig. $2 \mathrm{~B}$ ) and the $I_{\mathrm{pb}} / I_{\mathrm{pf}}$ ratio is always very close to unity (namely, $0.98 \pm 0.03$ ).

All these features indicate a diffusion controlled reversible electrochemical behaviour for the oxidation:

$\mathrm{Fc} \rightleftarrows \mathrm{Fc}^{+}+\mathrm{e}$

A similar behaviour was observed at the GCE for Fc in the other ILs as well as for $\mathrm{FCCOO}^{-}$and $\mathrm{FA}^{+}$in all the examined solvents. For the case of the high viscosity IL [P14,666][N(Tf $\left.)_{2}\right]$, only ferrocene was examined as the electroactive solute. Note that, since an Ag wire was used as a pseudo-reference electrode, no quantitative comparison of $E_{1 / 2}$ values of different analytes and/or in different IL can be performed. From a qualitative viewpoint it was observed that the oxidation of $\mathrm{FcCOO}^{-}$and $\mathrm{FA}^{+}$takes place at potential values not too far each other and, in almost all the examined ILs, the oxidation of the ionic Fc derivatives occurs at more positive potential values than the oxidation of neutral Fc.

On the basis of the observed electrochemical behaviour, diffusion coefficients values were calculated by the slopes of the linear Ip vs. $v^{1 / 2}$ plots, by applying the Randles-Sevcik equation [29]:

$I=2.69 \times 10^{5} n^{3 / 2} A D^{1 / 2} C v^{1 / 2}$

Diffusion coefficient values were measured in triplicate and relevant average values \pm maximum range are listed in Table 2 .

These data indicate that diffusion coefficients values of Fc and derivatives in the examined ILs are from 1 to 2 orders of magnitude lower than $D$ values in aqueous $[42,43]$ or acetonitrile solutions [44]. Comparison between data in Tables 1 and 2 confirms that $D$ values for the same redox probe decrease significantly with increasing the solvent viscosity. Because of the variability of the experimental conditions relevant to the data in Table 1, which come from different literature sources, care must be taken in trying to check quantitatively such a dependence.

For $D$ values already available in the literature some consideration can be done. For the case of Fc in [BMIm] $\left[\mathrm{N}(\mathrm{Tf})_{2}\right]$ the value determined by us at $20^{\circ} \mathrm{C}$, namely $2.9 \times 10^{-7} \mathrm{~cm}^{2} \mathrm{~s}^{-1}$, is in reasonable agreement with the literature values of $3.77 \times 10^{-7} \mathrm{~cm}^{2} \mathrm{~s}^{-1}$ [45], measured at $26^{\circ} \mathrm{C}$. Higher temperature means lower viscosity and higher $D$ values; it was reported that each two-degree shift results in $10 \%$ change of the IL viscosity [46], so that, taking into account this factor, the two values are almost the same. Note that recently, for the same probe and IL, Vorotyntsev measured at $20^{\circ} \mathrm{C}$ a $D$ value of $1.7 \times 10^{-7} \mathrm{~cm}^{2} \mathrm{~s}^{-1}$ [46]. On the other hand, the $D$ value determined by us for Fc in [BmPy] $\left[\mathrm{N}(\mathrm{Tf})_{2}\right]$, namely $0.7 \times 10^{-7} \mathrm{~cm}^{2} \mathrm{~s}^{-1}$, is about three times smaller than the value $2.31 \times 10^{-7} \mathrm{~cm}^{2} \mathrm{~s}^{-1}$, measured by Compton's group [45]. In this case, taking into account the temperature dependence of $D$ values reduces the scattering between our and the Compton's group datum, but does not cancel it, so that other factors, including the different measurement technique (that is CV vs. double step chronoamperometry at ultramicroelectrodes), should be considered.

In any case, the cross-comparison of our $D$ values, all measured with the same procedure, indicates that the diffusion coefficients of the ionic derivatives are smaller than those of neutral ferrocene. This suggests the occurrence of a stronger interaction of the ILs with the ionic ferrocenes. In ILs, the lowering of diffusion coefficients for ionic species with respect to their neutral analogues is indeed documented in the literature $[11,12]$. Compton et al. demonstrated [45], that the $D$ value for neutral ferrocene is much larger than $D$ for the ferricinium cation, the same holding also for the cobaltocene/cobalticinium couple. A comparable unequality in diffusion coefficients of the butylviologen dication vs. the mono-cationic radical was reported to be the cause of differences in reduction peak currents for the two species in [BMIm] $\left[\mathrm{BF}_{4}\right]$ [15].

\subsection{Au-macro}

The electrochemical behaviour of neutral $\mathrm{Fc}, \mathrm{FcCOO}^{-}$and $\mathrm{FA}^{+}$ at the Au-macro is reversible or quasi-reversible in the ILs containing the $\left[\mathrm{N}(\mathrm{Tf})_{2}\right]^{-}$anion, with features comparable with those obtained at the GC-macro. On the other hand, in the ILs containing the $\left[\mathrm{N}(\mathrm{CN})_{2}\right]^{-}$anion significant differences and complications are observed at the Au-macro. Fig. 3 shows the $\mathrm{CVs}_{\text {sor }} \mathrm{FcCOO}^{-}$in [BMIm] $\left[\mathrm{N}(\mathrm{CN})_{2}\right]$.

An oxidation peak with almost symmetrical shape is observed with the peak potential shifting from 0.660 to $0.710 \mathrm{~V}$ when increasing the scan rate. In the backward scan a small reduction peak is observed at about $0.570 \mathrm{~V}$. The oxidation peak scales linearly with the scan rate (see insert in Fig. 3), in agreement with the occurrence of an adsorption controlled process [29]. This can be explained taking into account that the $\left[\mathrm{N}(\mathrm{CN})_{2}\right]^{-}$anion can adsorb on gold, modifying the electrode surface and acting as a bridge in the following adsorption and oxidation of the redox probe.

The situation observed for ferrocene in the same IL is shown in Fig. 4. Now, in the oxidation scan two peaks are observed, suggesting the occurrence of two following processes. The current of the first anodic peak depends linearly on the square root of the scan rate, while the current of the second anodic peak scales directly with $v$ (not shown). As a consequence of such a different dependence on the scan rate, the first peak is the prevailing one at low scan rates (e.g. $0.020 \mathrm{~V} \mathrm{~s}^{-1}$ ) while the second peak increases when increasing the scan rate, up to being very well detected at $v>0.5 \mathrm{~V} \mathrm{~s}^{-1}$. These evidences suggest that the first peak is related to the oxidation of diffusing Fc while second peak can be due to adsorption on Au, via adsorbed $\left[\mathrm{N}(\mathrm{CN})_{2}\right]^{-}$, of electrogenerated $\mathrm{Fc}^{+}$. Similarly complex voltammetric patterns were observed at the Aumacro for the other redox probes in [BMPy] $\left[\mathrm{N}(\mathrm{CN})_{2}\right]$.

In the following part of this research we were interested in investigating mainly the role of the solvent on the diffusion of the analyte to the nanoelectrodes, therefore we chose to avoid any complication by adsorption or other non-diffusion controlled processes by focusing our attention on the behaviour of ferrocene and its derivatives in the $\left[\mathrm{N}(\mathrm{Tf})_{2}\right]$ containing ILs.

\subsection{Voltammetry with NEEs}

Fig. 5A shows the CVs recorded at three different scan rates with a NEE in $5 \mathrm{mM}$ Fc in [BMPy][N(Tf $\left.)_{2}\right]$. 
(A)

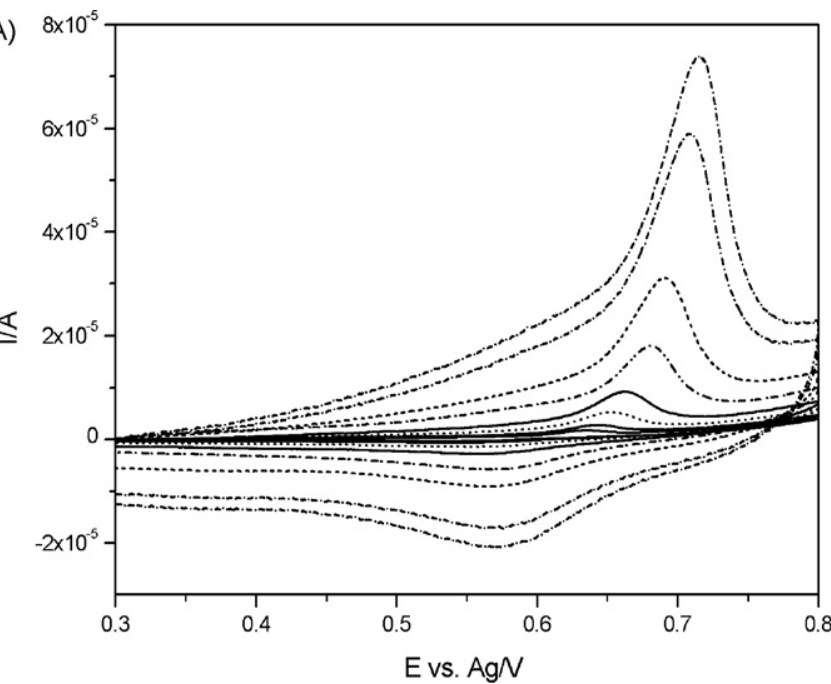

(B)

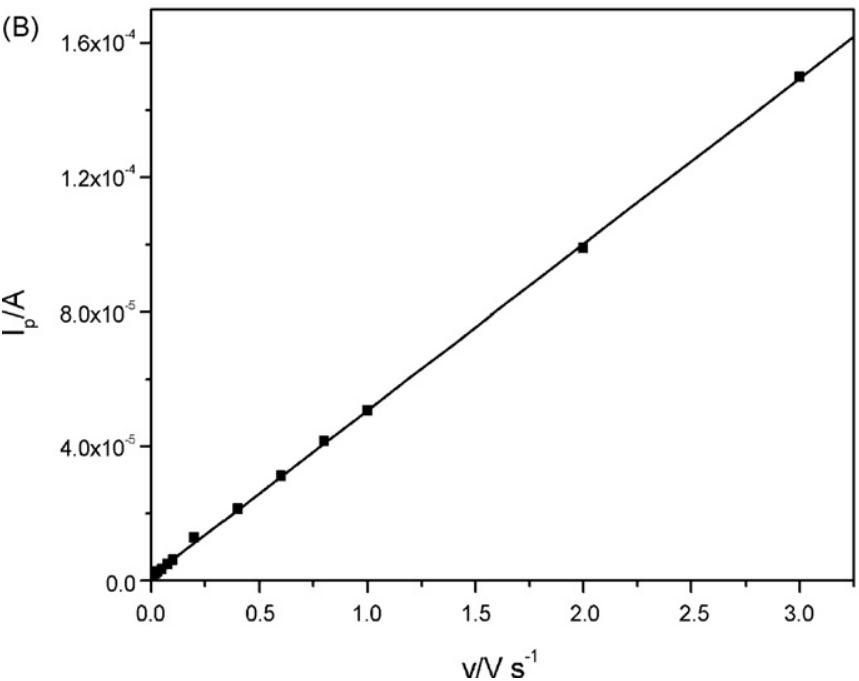

Fig. 3. (A) Cyclic voltammograms of $1 \mathrm{mM} \mathrm{FcCOOH}$ in $[\mathrm{BMIm}]\left[\mathrm{N}(\mathrm{CN})_{2}\right]$ recorded at an Au-macro electrode (geometric area $0.07 \mathrm{~cm}^{2}$ ), at different scan rates: 10, 20 , $50,100,200,400,800$ and $1000 \mathrm{mV} \mathrm{s}^{-1}$; peak currents scale with the scan rate. (B) Dependence of the anodic peak current on the scan rate.

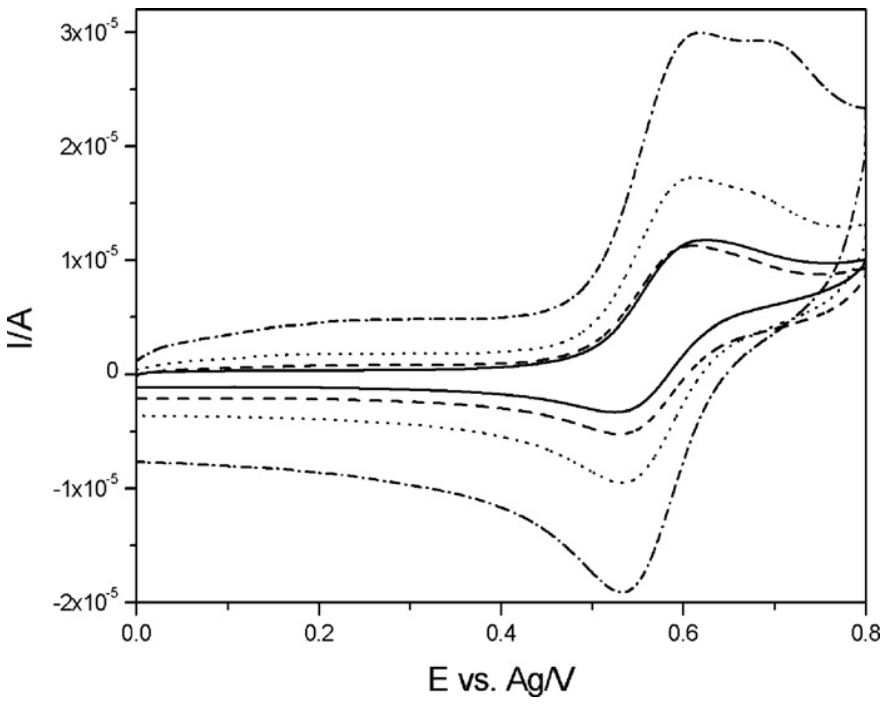

Fig. 4. Cyclic voltammograms of $1 \mathrm{mM}$ Fc in $[\mathrm{BMIm}]\left[\mathrm{N}(\mathrm{CN})_{2}\right]$ recorded at an Au-macro electrode at different scan rates: $50,100,200$ and $500 \mathrm{mV} \mathrm{s}^{-1}$; other parameters as in Fig. 3.
At low scan rates peak shaped voltammograms are recorded which become sigmoidally shaped at higher scan rates, however with a shift detectable between the forward and backward patterns. As shown in Fig. 5B and C, similar behaviours are observed in [BMIM] $\left[\mathrm{N}(\mathrm{Tf})_{2}\right]$ and $\left[\mathrm{P}_{14,666}\right]\left[\mathrm{N}(\mathrm{Tf})_{2}\right]$, respectively; note also that similarly sigmoidally shaped CV patterns were previously observed at NEEs for the case of $\mathrm{FA}^{+}$or heptylviologen cations in [BMIm] $\left[\mathrm{BF}_{4}\right]$ [15]. On the basis of recent reports [26], the CV shape observed at high scan rates could be considered typical of the mixed diffusion layers regime, which is observed when there is a partial overlapping of individual diffusion layers. However, even the contribution of the double-layer charging current $\left(I_{\mathrm{C}}\right)$ cannot be neglected, since such a capacitive current can also be responsible for the lack of overlap between the forward and backward voltammetric patterns. Note that in IL double-layer charging currents are significantly higher than that in water. Moreover, to reach the pure radial regime with NEEs it is necessary to operate at relatively high scan rates and $I_{C}$ scales directly with $v$; for instance, for our NEEs at $500 \mathrm{mV} \mathrm{s}^{-1}, I_{\mathrm{C}}$ is estimated around $300 \mathrm{nA}$ in $\left[\mathrm{P}_{14,666}\right]\left[\mathrm{N}(\mathrm{Tf})_{2}\right]$ vs. $60 \mathrm{nA}$ in water.

In Fig. 5A some sloping of the $\mathrm{CV}$ pattern is also observed. This could be due to some slowness of the electron transfer kinetics, but also the contribution of some residual un-compensated IR-drop cannot be excluded; very high viscosity IL such as $\left[\mathrm{P}_{14,666}\right]\left[\mathrm{N}(\mathrm{Tf})_{2}\right]$ are indeed characterized also by very high ohmic resistance [47] which cannot necessarily be fully corrected by instrumental IRdrop compensation.

Plots in Fig. 6 report the typical dependence of the maximum current (that is the plateau current or the peak current at high or low scan rates, respectively) as a function of the scan rate (A) and square root of the scan rate (B). In order to make the comparison clearer, currents were normalized over the maximum current recorded for each set of measurements in the same IL.

At very low scan rates, the peak current increases linearly with $v^{1 / 2}$, indicating the operativity of total overlap conditions. At very high scan rates, the current becomes practically independent of the scan rate, while at intermediate scan rate a complex dependence is operative. These plots put in evidence that the maximum value of the scan rate up to which $I_{\mathrm{p}}$ increases linearly with $v^{1 / 2}$ depends on the nature of the IL, scaling inversely with the solvent viscosity. Such a $v$ maximum is approximately $50 \mathrm{mV} \mathrm{s}^{-1}$ in $\left[\mathrm{P}_{14,666}\right]\left[\mathrm{N}(\mathrm{Tf})_{2}\right]$ and $90 \mathrm{mV} \mathrm{s}^{-1}$ in [BMPy][N(Tf $\left.)_{2}\right]$; data in [BMIm] $\left[\mathrm{N}(\mathrm{Tf})_{2}\right]$ are more scattered.

The plots show that also the scan rate at which the current responses start to be independent of the scan rate, depends on the nature of the ILs. Note that the observation of such an independency is indicative of a strong tendency to the PR regime, particularly evident for $\left[\mathrm{P}_{14,666}\right]\left[\mathrm{N}(\mathrm{Tf})_{2}\right]$. Again, the scan rate at which such a situation is achieved scales inversely with the solvent viscosity, that is higher is the viscosity, lower is the scan rate at which independency starts to be detected.

A very practical graphical representation of the transitions between different diffusion regimes at ordered arrays of microelectrodes was introduced very recently by Guo and Lindner [26]. Even if NEEs are random distributed, some interesting consideration can be extrapolated (at least semi-quantitatively) also for the NEE case. The limit of the different diffusion zones is defined on the basis of values of two dimensionless parameters, namely, the dimensionless distance:

$d^{*}=\frac{d}{a}$

where $d$ is the center-to-center distance between adjacent microelectrodes, and $a$ is the microelectrode radius; and the dimensionless scan rate:

$V=\frac{n F v a^{2}}{(4 R T D)}$ 

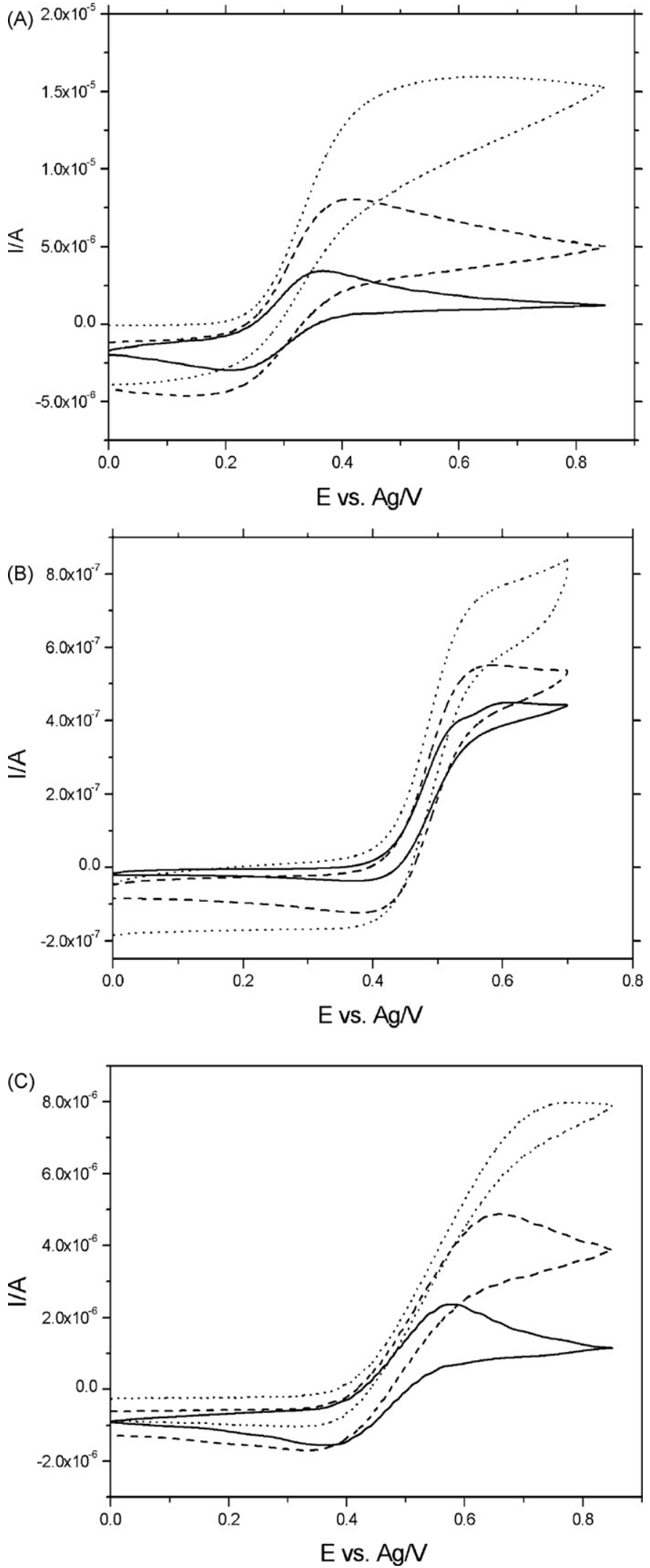

Fig. 5. Cyclic voltammograms recorded at different scan rates at a NEE (geometric area $0.07 \mathrm{~cm}^{2}$; active area $0.004 \mathrm{~cm}^{2}$ ): (A) $20 \mathrm{mM} \mathrm{Fc} \mathrm{[BMPy][N(Tf)2];} \mathrm{(B)} 5 \mathrm{mM} \mathrm{Fc} \mathrm{in}$ [BMIm] $\left[\mathrm{N}(\mathrm{Tf})_{2}\right]$; (C) $50 \mathrm{mM} \mathrm{Fc}\left[\mathrm{P}_{14,666}\right]\left[\mathrm{N}(\mathrm{Tf})_{2}\right]$. Scan rates: full line $5 \mathrm{mV} / \mathrm{s}$; dashed line $50 \mathrm{mV} \mathrm{s}^{-1}$; dotted line $500 \mathrm{mV} / \mathrm{s}$.
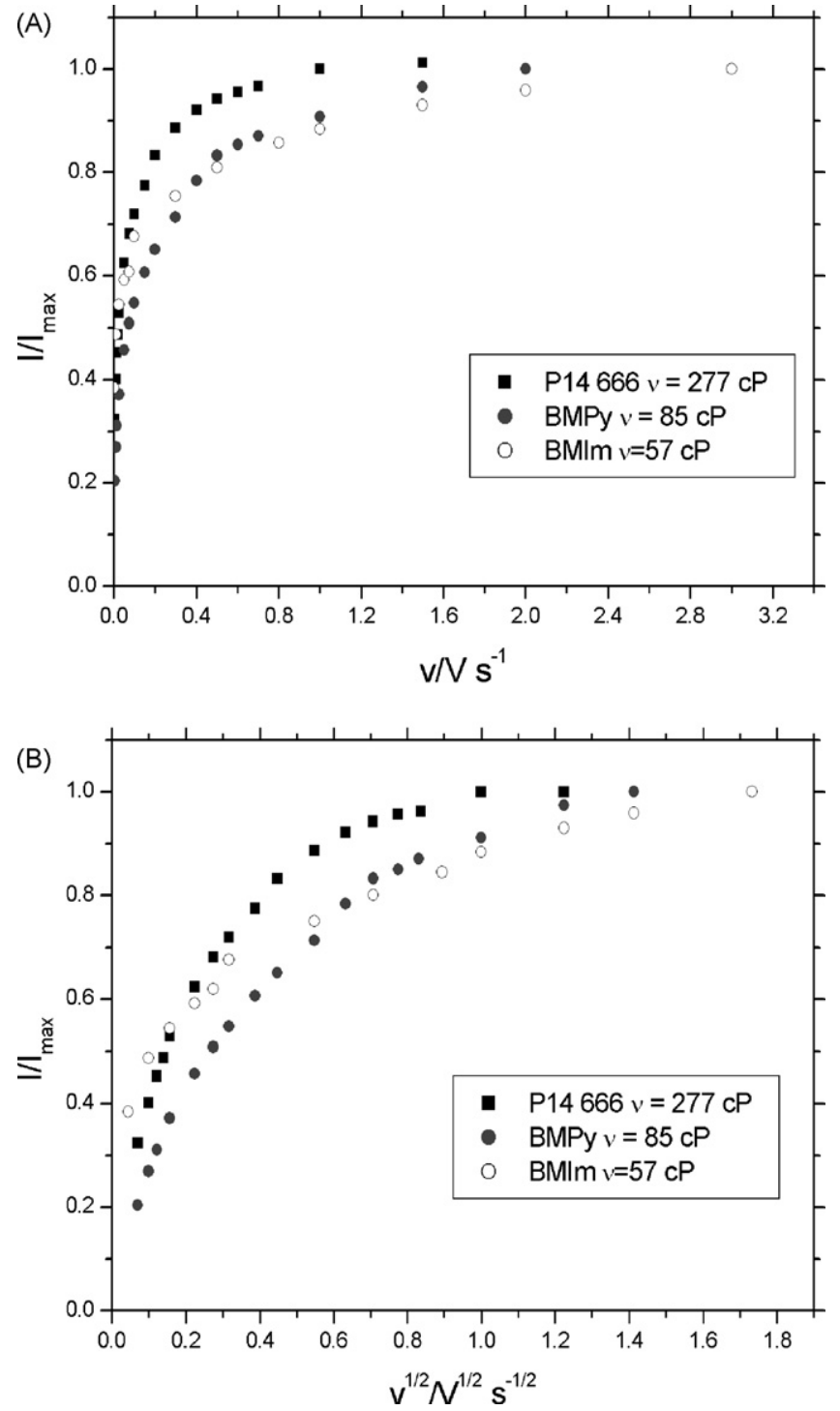

Fig. 6. Dependence of the $I / I_{\max }$ ratio on the scan rate (A) and on the square root of the scan rate (B) for ferrocene oxidation at a NEE in: (๑) [BMPy] $\left[\mathrm{N}(\mathrm{Tf})_{2}\right]$; $(\bigcirc)$ $[\mathrm{BMIm}]\left[\mathrm{N}(\mathrm{Tf})_{2}\right] ;(\mathbf{\square})\left[\mathrm{P}_{14,666}\right]\left[\mathrm{N}(\mathrm{Tf})_{2}\right]$.

where $n$ is the number of electrons transferred, $F$ is the Faraday constant, $R$ is the universal gas constant, $T$ is the absolute temperature, $v$ is the scan rate. Note that the dimensionless scan rate increases with decreasing $D$. Sigmoidally shaped CV with relevant shift in the forward vs. backward voltammetric pattern characterizes case IV, while the TO case corresponds to the $\mathrm{V}$ zone.

The geometrical characteristic of our NEEs [38], set the average $d^{*}$ value slightly above 10 . According to Ref. [26], under such $d^{*}$ conditions, it is very difficult to achieve the pure radial regime even at very high $V$ values and the transition from Total overlap to mixed diffusion can be more easily observed. The experimental scan rate at which the transition from TO $\rightarrow$ MDL (or V $\rightarrow$ IV) occurs in solvents where the same analyte have different diffusion coefficients, can be calculated by rearranging equation (6) according to:

$v \geq \frac{V 4 R T D}{\left(n F a^{2}\right)}$

Eq. (5) agrees, at least semi-quantitatively, with what experimentally observed, since the transition scan rate increases with $D$ and decreases with the IL viscosity. 

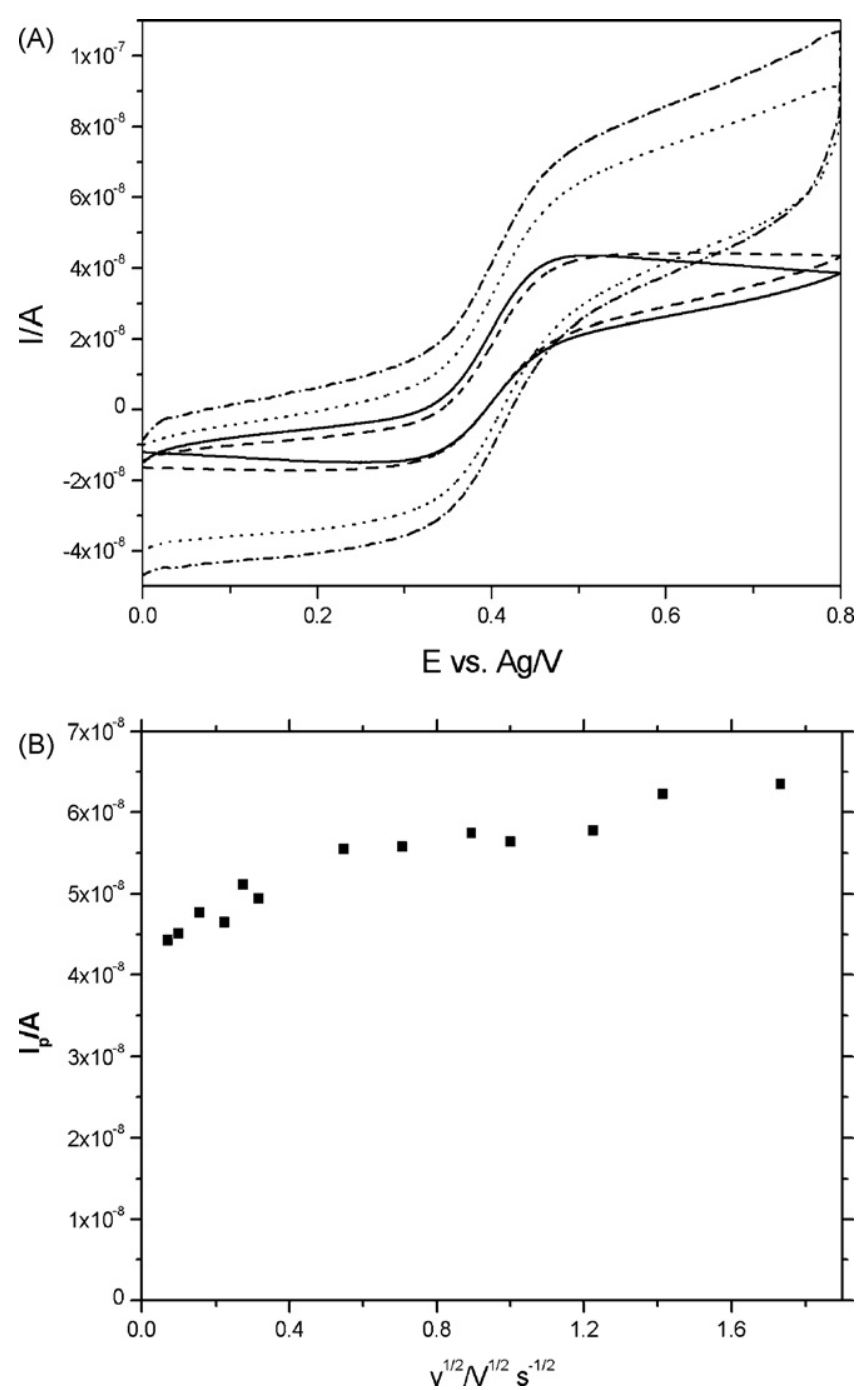

Fig. 7. (A) Cyclic voltammograms of $1 \mathrm{mM} \mathrm{FcCOO}^{-}$in [BMPy] $\left[\mathrm{N}\left(\mathrm{Tf}_{2}\right)\right]$ recorded at a NEE at different; scan rates: full line $2 \mathrm{mV} \mathrm{s}^{-1}$; dashed line $5 \mathrm{mV} \mathrm{s}^{-1}$; dotted line $500 \mathrm{mV} \mathrm{s}^{-1}$; dashed-dotted line $800 \mathrm{mV} \mathrm{s}^{-1}$. (B) Dependence of the maximum (plateau) current on the square root of the scan rate.

This also agrees with the evidence that in water, the TO $\rightarrow$ MDL transition is not observed neither at quite high scan rates $(v>$ $10 \mathrm{~V} \mathrm{~s}^{-1}$ ), while in the ILs it can be observed at more easily accessible scan rates.

Further studies were performed focusing on the CV behaviour on NEEs of the ionic probes $\mathrm{FcCOO}^{-}$or $\mathrm{FA}^{+}$in the ILs. As shown for instance in Fig. 7 for the typical case of $1 \mathrm{mM} \mathrm{FcCOO}^{-}$in $[\mathrm{BmPy}]\left[\mathrm{N}(\mathrm{Tf})_{2}\right]$, both the shape of the $\mathrm{CV}$ (Fig. 7A) as well as the scarce scan rate dependence of $I_{\max }$ (Fig. 7B) indicate that crosstalking between the nanoelectrodes is dramatically reduced for any of the scan rates explored.

The same happens in [BMIm] $\left[\mathrm{N}(\mathrm{Tf})_{2}\right]$ as well as for $\mathrm{FA}^{+}$in both the ILs (not shown), so indicating that the lowering of $D$ values related to the presence of the ionic charge in these redox probes has comparable effects as the lowering of $D$ for neutral Fc in ILs of very high viscosity. This behaviour is again explained taking into account the relevant role of diffusion coefficients, since $D$ values for $\mathrm{FA}^{+}$and $\mathrm{FcCOO}^{-}$in $[\mathrm{BMPy}]\left[\mathrm{N}(\mathrm{Tf})_{2}\right]$ and $[\mathrm{BMIm}]\left[\mathrm{N}(\mathrm{Tf})_{2}\right]$ are lower than $D$ values for neutral Fc (see Table 2 ) in the same ILs, but comparably small with respect to the $D$ value of neutral ferrocene in the highest viscosity solvent examined here, namely $\left[\mathrm{P}_{14,666}\right]\left[\mathrm{N}(\mathrm{Tf})_{2}\right]$.

\section{Conclusions}

This study points out some interesting characteristic in the diffusion behaviour at NEEs of ferrocene and its derivatives in the ILs examined. The lowering of diffusion coefficients related to increased solvent viscosity causes the change of the CV patterns from the total overlap situation to the mixed diffusion layer regime. In the highest viscosity ILs, such as $\left[\mathrm{P}_{14,666}\right]\left[\mathrm{N}(\mathrm{Tf})_{2}\right]$, we get close to achieve the pure radial regime, however the persistence of some shift in the forward vs. backward voltammetric pattern as well as the comparison with recent theories leave some doubts on whether the diffusion regime be finally PR or MDL. The geometrical characteristics of NEE prepared using commercial track-etch polycarbonate as the template, in particular the random distribution of the nanoelectrodes, does not help in solving this dichotomy. Other structure and geometries of the array need therefore to be implemented to achieve a better control of relevant geometrical parameters. Data both on NEEs and millimetre sized electrodes indicated, anyhow, slower diffusion for the ionic ferrocene derivatives with respect to neutral ferrocene, with no evident influence of the sign of the charge, since diffusion both of cationic $\mathrm{FA}^{+}$and anionic $\mathrm{FCCOO}^{-}$are similarly slowed down.

Finally, gold is not the electrode material of choice for measurements under diffusion control in $\left[\mathrm{N}(\mathrm{CN})_{2}\right]$ containing ILs, since this anion favours the adsorption of electroactive redox molecules on the electrode surface. No such problem was found in $\left[\mathrm{NTf}_{2}\right]$ containing ILs while at GC electrodes diffusion controlled processes are observed both in the presence of $\left[\mathrm{N}(\mathrm{CN})_{2}\right]$ and $\left[\mathrm{NTf}_{2}\right]$.

\section{Acknowledgments}

The authors thank COST D29 Action Group for a visit to QUB and APD thanks CYTEC Industries Inc. for the gift of tetradecyl(trihexyl)phosphonium chloride. This work was partially supported by MIUR (Rome).

\section{References}

[1] P.A.Z. Suarez, V.M. Selbach, J.E.L. Dullius, S. Einloft, C.M.S. Piatnicki, D.S. Azambuja, R.F. de Souza, J. Dupont, Electrochim. Acta 42 (1997) 2533.

[2] M. Galinski, A. Lewandowski, I. Stepniak, Electrochim. Acta 51 (2006) 5567.

[3] D.S. Silvester, R.G. Compton, Z. Phys. Chem. 220 (2006) 1247.

[4] P. Hapiot, C. Lagrost, Chem. Rev. 108 (2008) 2238.

[5] M. Kosmulski, R. Osteryoung, M. Ciszkowska, J. Electrochem. Soc. 147 (2000) 1454.

[6] U. Schroeder, J.D. Wadhawan, R.G. Compton, F. Marken, P.A.Z. Suarez, C.S. Consorti, R.F. de Souza, J. Dupont, New J. Chem. 24 (2000) 1009.

[7] V.M. Hultgren, A.W.A. Mariotti, A.M. Bond, A.G. Wedd, Anal. Chem. 74 (2002) 3151.

[8] R.G. Evans, O.V. Klymenko, P.D. Price, S.G. Davies, C. Hardacre, R.G. Compton, ChemPhysChem 6 (2005) 526.

[9] N. Fietkau, A.D. Clegg, R.G. Evans, C. Villagran, C. Hardacre, R.G. Compton, ChemPhysChem 7 (2006) 1041.

[10] O. Fontaine, C. Lagorst, J. Ghilane, P. Martin, G. Trippe, C. Fave, J.-C. Lacroix, P. Hapiot, J. Electroanal. Chem. 632 (2009) 88.

[11] M.C. Buzzeo, O.V. Klymenko, J.D. Wadhawan, C. Hardacre, K.R. Seddon, R.G. Compton, J. Phys. Chem., A 107 (2003) 8872.

[12] J. Ghilane, C. Lagrost, P. Hapiot, Anal. Chem. 79 (2007) 7383.

[14] S. Eisele, M. Schwarz, B. Speiser, C. Tittel, Electrochim. Acta 51 (2006) 5304.

[15] M. De Leo, L.M. Moretto, O. Buriez, P. Ugo, Electroanalysis 21 (2009) 392.

[16] P. Ugo, L.M. Moretto, in: C. Zoski (Ed.), Handbook of Electrochemistry, Elsevier, Amsterdam, 2007 (chapter 16).

[17] M. De Leo, F.C. Pereira, L.M. Moretto, P. Scopece, S. Polizzi, P. Ugo, Chem. Mater. 19 (2007) 5955.

[18] V.P. Menon, C.R. Martin, Anal. Chem. 67 (1995) 1920.

[19] D.W. Arrigan, Analyst 129 (2004) 1157.

[20] L.M. Moretto, S. Panero, B. Scrosati, P. Ugo, in: Y. Lin, S. Nalwa (Eds.) Handbook of Electrochemical Nanotechnology, vol. 1, American Scientific Publisher. Stevesnon Ranch, CA, USA, (2009) (chapter 4).

[21] C. Amatore, J.M. Saveant, D. Tessier, J. Electroanal. Chem. 147 (1983) 39.

[22] B.A. Brooks, T.J. Davies, A.C. Fisher, R.G. Evans, S.J. Wilkins, K. Yunus, J.D. Wadhawan, R.G. Compton, J. Phys. Chem. B 107 (2003) 1616 
[23] P. Ugo, L.M. Moretto, F. Vezzà, ChemPhysChem 3 (2002) 917.

[24] L.M. Moretto, N. Pepe, P. Ugo, Talanta 62 (2004) 1055.

[25] H.J. Lee, C. Beriet, R. Ferrigno, H.H. Girault, J. Electroanal. Chem. 502 (2001) 138

[26] J. Guo, E. Lindner, Anal. Chem. 81 (2009) 130.

[27] N. Godino, X. Borrisé, F.C. Munoz, F.J. del Campo, R.C. Compton, J. Phys. Chem. C 113 (2009) 11119.

[28] T.J. Davies, B.A. Brooks, A.C. Fosher, K. Yunus, S.J. Wilkins, P.R. Greene, J.D. Wadhawan, R.G. Compton, J. Phys. Chem. B 107 (2003) 6431.

[29] J.C. Hulteen, V.P. Menon, C.R. Martin, J. Chem. Soc. Faraday Trans. 92 (1996) 4029 .

[30] A.J. Bard, L.R. Faulkner, Electrochemical Methods, 2nd ed., Wiley, New York, 2001.

[31] R.G. Evans, O.V. Klymenko, C. Hardacre, K.R. Seddon, R.G. Compton, J. Electroanal. Chem. 556 (2003) 179.

[32] M.-J. Denga, P.-Y. Chenb, T.-I. Leonga, I.-W. Suna, J.-K. Changc, W.-T. Tsaic, Electrochem. Commun. 10 (2008) 213.

[33] D.R. MacFarlane, J. Golding, S. Forsyth, M. Forsyth, G.B. Deacon, Chem. Commun. (2001) 1430.

[34] D.R. MacFarlane, J. Sun, F. Golding, P. Meakin, M. Forsyth, Electrochim. Acta 45 (2000) 1271.
[35] P. Bonhote, A.-P. Dias, N. Papageogiou, K. Kalyanasundaram, M. Gratzel, Inorg. Chem. 35 (1996) 1168.

[36] S.V. Hill, J.L. Longridge, A. Williams, J. Org. Chem. 49 (1984) 1819.

[37] R.A. Benkeser, D. Goggin, G. Schroll, J. Am. Chem. Soc. 76 (1954) 4025

[38] B.K. Sweeney, D.G. Peters, Electrochem. Commun. 3 (2001) 712.

[39] M. De Leo, A. Kuhn, P. Ugo, Electroanalysis 19 (2007) 227.

[40] P. Ugo, N. Pepe, L.M. Moretto, M. Battagliarin, J. Electroanal. Chem. 560 (2003) 51.

[41] A. Lombardo, T.I. Bieber, J. Chem. Educ. 60 (1983) 1080.

[42] S. Daniele, M.A. Baldo, P. Ugo, G.A. Mazzocchin, J. Electroanal. Chem. 295 (1990) 95.

[43] E. Sabatani, I. Rubinstein, J. Phys. Chem. 91 (1987) 6663.

[44] J.E. Baurr, in: C.Zoski(Ed.), Handbook of Electrochemistry, Elsevier, Amsterdam, 2007 (chapter 19)

[45] E.I. Rogers, D.S. Silvester, D.L. Poole, L. Aldous, C. Hardacre, R.G. Compton, J. Phys. Chem. 112 (2008) 2729.

[46] M.A. Vorotyntsev, V.A. Zinovyeva, D.V. Konev, M. Picquet, L. Gaillon, C. Rizzi, J. Phys. Chem. B 113 (2009) 1085.

[47] M. Galiński, A. Lewandowski, I. Stępniak, Electrochim. Acta 51 (2006) 5567. 